\title{
DE NARRADOR A NARRADOR: UMA ANÁLISE ACERCA DA ADAPTAÇÃO NARRATIVA EM JOHNNY GOT HIS GUN, DE DALTON TRUMBO
}

\author{
Paulo Henrique Raulino dos Santos ${ }^{1}$ \\ Charles Albuquerque Ponte ${ }^{2}$
}

\begin{abstract}
Resumo: A adaptação de livros para o cinema apresenta inúmeras dificuldades, em especial como modificar o narrador verbal da literatura para o principal narrador, visual, do cinema, a câmera. Assim, propomos o desenvolvimento de uma análise da adaptação cinematográfica do livro Johnny vai à guerra, roteirizado e dirigido pelo autor do romance, Dalton Trumbo, em 1971. Para tanto, nos embasaremos nos pressupostos teóricos de Hutcheon (2012), Stam (2006) e Xavier (2003), com os quais traçamos um panorama histórico e prático acerca da área, bem como Chatman (1990) e Pouillon (1974) para a análise do narrador no filme e no livro. Apesar da diferença estética, a adaptação cinematográfica conseguiu cumprir a tarefa de transmutar o narrador "com" presente no livro para o narrador câmera, utilizando-se de recursos como fotografia e construção de planos.
\end{abstract}

Palavras-chave: Adaptação. Narrador. Dalton Trumbo. Johnny vai à Guerra.

\section{NARRATOR TO NARRATOR: AN ADAPTATION ANALYSIS ON JOHNNY GOT HIS GUN, BY DALTON TRUMBO}

\begin{abstract}
Adapting books to film presents many difficulties, especially how to modify the verbal narrator from literature to the main, visual narrator in film, the camera. Therefore, this work intends to develop an analysis of Johnny got his gun's adaptation, written and directed by the author of the novel, Dalton Trumbo, in 1971. In order to do so, the theoretical background will be provided by Hutcheon (2012), Stam (2009) and Xavier (2003), which give a historical and practical background about adaptation and its historical evolution, as well as Chatman (1990) and Pouillon (1974) for the narrator analysis in the novel and he film. Despite the aesthetic differences, the cinematic adaptation fulfilled its task, transporting the third person narrator "with" in the novel to the camera narrator, using cinematic resources such as photography and plane construction.
\end{abstract}

Key-words: Adaptation. Narrator. Dalton Trumbo. Johnny got his gun.

\footnotetext{
${ }^{1}$ Mestrando pelo Programa em pós-graduação em letras (PPGL-UERN).

${ }^{2}$ Professor adjunto na Universidade do Estado do Rio Grande do Norte.
} 


\section{Introdução}

Apesar da ubiquidade das adaptações na cena artísticas contemporânea, a tentação de julgar esse gênero criativo como inferior é ainda um dos mais constantes anátemas de consumidores e alguns estudiosos. Entretanto, tal discurso, frequentemente surgido sob a argumentação ora de que o autor da obra original raramente teria participação no processo de adaptação, ora haveria uma simplificação ou perda da pureza na transição, não é válido. Apresentamos neste artigo uma tentativa de se trazer luz a um processo dessa natureza que toma lugar em uma relação decididamente ímpar, na qual o mesmo autor é responsável pelas duas obras, literária e cinematográfica, realizando um comparativo entre o romance Johnny vai à guerra, publicado pelo americano Dalton Trumbo (19051976) em 1939, e a película homônima, roteirizada e dirigida pelo próprio escritor em 1971, focando, exclusivamente, no processo de transposição do narrador do livro para a obra fílmica.

Johnny vai à guerra (Johnny got his gun, no original em inglês) narra a história de Johnny, um jovem soldado americano que, após ser atingindo por um artefato bélico mortal durante a Primeira Guerra Mundial, perde braços, pernas, parte do rosto, audição e visão, restando-lhe apenas suas funções cognitivas presas a um corpo em estado vegetativo. O livro se restringe integralmente à mente da personagem, afixando ao narrador as sensações e pensamentos desenvolvidos pela personagem no enredo. É exatamente a restrição do livro a esse interior psicológico, seus sonhos e delírios que validam o estudo comparativo com sua adaptação, dada a complexidade em expressar fatores mentais e abstratos no cinema. Procuraremos, tendo por base os pressupostos teóricos dos estudos da narração literária e cinematográfica, explicitar as escolhas efetuadas durante o procedimento adaptativo, delineando um paralelo entre os narradores, explicitando as principais mudanças, suas motivações e funções para todo da obra.

Stam (2006) afirma ser possível às adaptações funcionarem como uma forma de crítica, positiva ou negativa, à obra adaptada, ao desenvolverem, no lugar de uma materialização direta da obra fonte, uma “[...] leitura do romance, que não está[ria] necessariamente subordinada a ele 
ou atuando como um parasita de sua fonte" (p. 22). Tal característica mostra que nem sempre a visão do adaptador necessita estar subordinada à do criador da fonte, uma vez que abre a possibilidade para a elaboração tanto de um desenvolvimento crítico-analítico da obra, quanto para a validação de uma total reformulação dessa construção prévia, podendo inclusive, ser criada uma obra inédita, apresentando traços da que a precede ${ }^{1}$.

Entretanto, muitas das opiniões negativas formuladas acerca da adaptação são, na verdade, preconceituosas e moralistas, havendo ainda quem defenda que o cinema, ao desenvolver adaptações de obras clássicas, prestaria um desserviço à literatura, e que, por sua vez, profana, deforma e viola a obra fonte ( $c f$. STAM, 2006, p. 19). De fato, para a grande maioria dos expectadores que conhecem o texto anterior - e isso é justificável sobretudo em decorrência da ligação afetiva com a obra -, o produto final é visto como algo estritamente conectado à fonte, sendo exigido um nível maior de respeito e fidelidade na produção. Contudo, a conotação dos termos usados por grande parte dos críticos e adeptos desse tipo de pensamento é, em sua maioria, pejorativa e pesada:

"Infidelidade" carrega insinuação de pudor vitoriano; "traição" evoca perfídia ética; "abastardamento" conota ilegitimidade; "deformação" sugere aversão estética e monstruosidade; "violação" lembra violência sexual; "vulgarização" insinua degradação de classes; e "profanação" implica sacrilégio religioso e blasfêmia (STAM, 2006, p. 20).

Tal problemática coloca em pauta a necessidade de encarar cada produção adaptada individualmente, dissociando uma da outra. Mais do que apenas adaptativas, as relações firmadas por ela extrapolam o mero viés da inspiração e, muitas vezes, da própria recontagem, figurando como de extrema importância para a atualização de narrativas que, em decorrência do distanciamento cultural e temporal, seriam impossibilitadas na contemporaneidade.

\footnotetext{
${ }^{1}$ Em seu livro Uma teoria da adaptação, Hutcheon (2011, p. 22) cita grandes nomes da literatura e da dramaturgia clássica que se utilizaram da adaptação como ponto de partida para vários de seus trabalhos, como Ésquilo e Shakespeare. No entanto, em geral esses autores optaram por recontar várias narrativas de sua época, porém, com uma nova abordagem, seja para adaptá-las para um público específico ou pelo simples desejo de inserir nelas suas próprias marcas e visões de mundo.
} 


\section{Johnny verbal: o ponto de vista cego}

É no contexto caótico do entre guerras que encontramos os primeiros trabalhos do escritor e roteirista norte-americano Dalton Trumbo (1905-1976). Um dos mais proeminentes nomes da cinematografia da época, ficou conhecido por ter seu nome incluído na lista negra do cinema americano, também denominada de "os 10 de Hollywood", grupo de atores, roteiristas e diretores perseguidos e presos durante as décadas de 1940 e 1950 por fazerem parte do Partido Comunista Americano.

Na literatura, área que primeiro atuou, escreveu dez livros, sendo o de maior destaque Johnny vai à guerra (Johnny got his gun). Ambientado na primeira guerra mundial, intitulada "a guerra para acabar com todas as guerras" ou ainda "a guerra pela segurança da democracia", o livro descreve os fatos referentes à personagem Joe Bonham, um jovem recruta que acaba ferido em campo, acordando atordoado, algum tempo depois, no hospital. É exatamente a grave deficiência da personagem que acaba por afetar a noção espaço-temporal da narrativa, limitada, em sua totalidade, à mente da personagem. Para que seja possível um maior didatismo na análise, distinguimos ambas dentro de três categorias: realidade, na qual temos acesso à percepção direta da personagem acerca do "mundo real"; as lembranças, através das quais visualizamos o passado da personagem; e, por fim, os sonhos e delírios, facilmente confundidos com as lembranças em decorrência da narração truncada e fragmentada, desenvolvida pelo autor na tentativa de aproximar a escrita do caos psicológico da mente humana. Para tanto se utiliza de um recurso diferenciado, porém, bastante difundido na época em que a obra foi escrita: o fluxo de consciência. Dessa forma, temos um romance que decorre, em sua totalidade, na mente da personagem Johnny, com o auxílio desse narrador em terceira pessoa que Pouillon (1974, p. 54) chama de “narrador 'com'”, uma vez que permanece grudado à personagem, limitandose à percepção deste. Ou seja, temos "[...] um único personagem que constituí o centro da narrativa, ao qual se atribui uma atenção maior ou, em todo caso, 
diferente da que se atribui aos demais" (POUILLON, 1974, p. 54). Na obra esse fator apresenta-se de maneira bastante clara, como vemos no trecho²:

Ele podia imaginá-la correndo através dos corredores. Ele podia ouvi-la fazendo barulho como se fosse um fantasma barulhento através dos corredores da morte. Ele podia senti-la correndo de enfermaria para enfermaria e da enfermaria dos aleijados para a enfermaria dos surdos para a enfermaria dos cegos e para a enfermaria dos mudos convocando a todas as pessoas do hospital gritando para eles a notícia da maravilha que havia ocorrido. (TRUMBO, 1989, p. 216, grifo nosso)

Em decorrência da limitação do narrador à personagem, cabe a ele imaginar, juntamente com este, os acontecimentos presenciados por outras personagens, por não haver, durante a narrativa, nenhuma fuga desse narrador para fora do aprisionamento mental do Johnny. Consequentemente, "vemos muito bem [...] o que se passa com ele, mas somente na medida em que o que se passa com alguém aparece [para ele] [...]" (POUILLON, 1974, p. 54). Os fatos que cercam esses terceiros somente tornam-se concretos para o narrador a partir do desenvolvimento interativo e simultâneo com a personagem.

Também destacamos nessa citação a presença da escrita em fluxo de consciência. Em nosso corpus, identificamos a construção de um padrão ímpar, no qual as vírgulas são removidas para possibilitar ao leitor a sensação, tanto da falta de nexo entre as sentenças, expediente comum ao pensamento, quanto da continuidade e descontinuidade que experimentamos quando reclusos as nossas mentes.

A realidade externa à personagem figura como uma das dimensões mais complexas de serem compreendidas, tanto para a personagem quanto para o narrador. Sua limitação à mente faz com que toda a complexidade comum a construção do espaço seja apreendida, basicamente, através da percepção sensorial da personagem, sendo feita de diferentes modos durante o decorrer da narrativa, variando a partir de suas interações com o espaço e as demais personagens.

\footnotetext{
${ }^{2}$ Todas as traduções do romance são nossas.
} 
Em um primeiro momento, o que ocorre é a percepção mediante as vibrações resultantes da movimentação das personagens, como vemos no seguinte trecho: "Durante o segundo ano no novo tempo de seu mundo nada aconteceu exceto que uma noite uma enfermeira tropeçou e caiu no chão criando uma boa vibração na sua cama" (TRUMBO, 1989, p. 154). Em contrapartida, a compreensão incerta que, até certo ponto, personagem e narrador compartilham em relação ao espaço físico que o cercam, se desfaz quando adentramos o terreno do "não real". Quando penetramos os sonhos, lembranças e devaneios, percebemos um crescimento no que se refere ao acesso desse narrador:

Ambos ficaram deitados no sofá olhando para ele. Ele parecia um anão crescido pelas costas curvadas em decorrência dos vinte e oito anos nas minas de carvão em Wyoming. Vinte e oito anos na mina com um cartão da I.W.W. ${ }^{3}$ e amaldiçoando todo mundo. Ele ficou parado olhando com raiva para eles e eles não faziam qualquer movimento. (TRUMBO, 1989, p. 30)

Isso se torna totalmente justificável, uma vez que a concepção de “estar 'com' alguém [...] não é ter deste alguém uma consciência refletida, não é conhecê-lo, é ter com ele a mesma consciência irrefletida de si mesmo" (POUILLON, 1974, p. 58). Sendo assim, o narrador não detém um conhecimento prévio do que seriam as lembranças da personagem, mas passa a compartilhar "com" ele a mesma memória, desbravando simultaneamente a sua narração para o público.

No tocante aos sonhos e devaneios, temos algo que se adapta à confusão perceptiva enfrentada pela personagem nos primeiros momentos da narrativa. Vemos isso em dois momentos específicos, sendo o primeiro ainda no parágrafo inicial do texto, no qual a personagem pensa ouvir o som de um telefone:

\footnotetext{
${ }^{3}$ I. W. W. (Industrials workers of the world) - em português: Trabalhadores industriais do mundo - é um sindicato baseado na democracia laboral e autogestão trabalhadora, que teve sua origem nos Estados Unidos da América durante o século XIX. O movimento prega uma união da classe trabalhadora que unifica princípios socialistas e anarquistas de maneira a sobrepujar o capitalismo. Ver em: http://www.iww.org/content/about-iww.
} 
Ele desejou que o telefone parasse de tocar. Já era ruim o bastante estar doente e ainda mais com um telefone tocando a noite toda. Cara ele estava doente. E não era de nenhum dos vinhos amargos da França. Um homem não conseguiria beber tanto para ficar com a cabeça daquele jeito. [...] A droga do som deveria estar do outro lado do mundo. Ele teria que caminhar por uns dois anos para chegar até ele. (TRUMBO, 1989, p. 3)

Para o segundo momento, tomamos por base o seguinte trecho:

O rato o estava devorando agora. Ele podia sentir os seus pequenos dentes afiados enquanto ele mordia as extremidades do seu ferimento ele sentia os rápidos movimentos do corpo do rato à medida que ele mastigava. Então ele iria enterrar as suas patas e retirar mais um pouco de carne e isso iria machucar e ele mastigaria novamente. (TRUMBO, 1989, p. 91-92)

Nesse ponto da narrativa, fica claro para o leitor a situação debilitada em que a personagem se encontra. Entretanto, em decorrência da permanente limitação do narrador à consciência da personagem, quando ela é afligida pela fantasia de um rato que o tenta devorar todas as noites, é incontestável o teor de dúvida que é imputado à trama. Nenhum dos dois consegue se situar de maneira satisfatória nesses momentos, quando nem mesmo o narrador consegue idealizar que tudo não passa de um momento de confusão da personagem ao confundir o tubo que está conectado a ele com um animal:

As mãos da enfermeira estavam sobre ele. [...] Ele percebia agora que o rato havia sido apenas um sonho. Ele estava tão aliviado de descobrir isso que por alguns segundos ele quase esqueceu seu medo. E então relaxando sobre os cuidados da enfermeira ele gelou por dentro percebendo que o sonho do rato poderia vir outras vezes. (TRUMBO, 1989, p. 93-94)

A perspectiva adotada pelo narrador se torna, portanto, uma característica peculiar do romance, obviamente, impossível de comunicar no cinema, posto que, sendo uma arte primordialmente visual, somente um filme experimental arriscaria uma tela sem imagens na tentativa de emular a 
incapacidade de uma personagem sem visão. No entanto, há outras maneiras de fazer o espectador perder a noção de espaço e tempo, como veremos a seguir, na análise do filme.

\title{
Johnny visual: narração e ponto de vista
}

Se para o filme tomarmos a relação simbiótica desenvolvida entre narrador e a personagem, iremos nos deparar com uma complexidade no mínimo interessante. Transportar uma narrativa com um alto teor psicológico como a desenvolvida por Trumbo para as telas não é tarefa fácil, ficando a critério do próprio diretor desenvolver adequações para um processo narratológico desta natureza.

Inicialmente, tomando por base os dois narradores aqui envolvidos - terceira pessoa na obra e narrador-câmera no filme -, é indispensável trazer à tona uma breve apresentação acerca da dicotomia mimesis e diegesis (mostrar e contar), que nos auxiliará na compreensão acerca da posição de cada narrador na sua área de atuação específica. Chatman (1992), postula que

\begin{abstract}
Em narrativas "contadas", como épicos e a maioria dos romances, a função narrativa é designada por um conjunto de significantes que são "arbitrários", dissimilares às ações, personagens ou aos espaços que eles significam. Em narrativas "mostradas", como narrativas fílmicas, ambas personagens e ações tendem a ser representadas de maneiras icônicas ou motivadas. (CHATMAN, 1990, p. 112, tradução nossa)
\end{abstract}

São exatamente esses dois lados da mesma moeda narratológica, o contar e o mostrar, que irão diferenciar o papel desempenhado pelo narrador nas mídias em questão. No livro, presenciamos a construção de toda a decorrente das palavras, de maneira que é o leitor que infere a elas o caráter de materialidade. No filme, ao se ocupar apenas em "mostrar" aquilo que ocorre, temos a materialização da ação, fato que delega à plateia o elemento de entretenimento contemplativo do que transcorre na tela, bem como a sua livre interpretação.

Em contrapartida ao narrador em terceira pessoa "com" desenvolvido no livro, o filme se utiliza do narrador-câmera, correspondente 
direto do primeiro na mídia cinematográfica. Entretanto, este narradorcâmera constrói a narrativa de maneira mimética, "mostrando", inferindo através dos vários recursos visuais um significado geral para a trama. No longa-metragem, esse narrador desempenha um trabalho análogo ao ministrado pelo narrador "com" na obra, mantendo-se, de certa forma, preso à personagem, observando a narrativa a partir de seu ponto de vista. É trabalho desse narrador desempenhar a função de apresentar a história de maneira que a personagem possa deter uma importância suprema na obra ( $c f$. CHATMAN, 1990, p. 147).

É resultante desse fator, predominante na narrativa, que veremos durante todo o filme um olhar que parece circular a personagem, orbitando à medida que enquadra cenário e personagens. Uma boa cena para observarmos essa característica toma forma em uma sequência onde, percebendo haver a recorrência de um padrão nos espasmos de seu paciente, a recém-chegada enfermeira requisita a presença de um médico para aplicar algum calmante que aliviasse o sofrimento, mas que somente nós sabemos ser a insatisfação deste com a sua desconsoladora situação (1h30min.). Enquadrados em um único plano sequência, observamos médico, enfermeira e paciente interagirem, toda a cena sendo concebida a partir de uma câmera que privilegia a personagem apesar de sua "inferioridade" na trama para as demais. Essa centralização orbital toma forma através de pequenos movimentos panorâmicos, primeiro para esquerda, seguindo o médico à medida que este prepara a injeção, centralizando-se durante a aplicação do remédio até, por fim, ser finalizada com o direcionamento da câmera para a direita, à medida que o médico os deixa.

É constante a utilização dos planos sequência no filme. De fato, seu emprego é de extrema importância na indução do sentimento de inquietação da personagem ao público, uma vez que sua aplicação impõe ao expectador a necessidade de uma maior concentração, bem como pressupõe uma maior tensão decorrente da diminuição dos vários cortes a que estamos acostumados. Esse ponto, unido à percepção reduzida do Johnny, nos coloca como um tipo de prolongamento dos sentidos e sentimentos dele na narrativa, à medida que esses inexistem para o mundo externo a ele, sendo exclusividade nossa e do narrador câmera a extensão do seu desespero. 
A fotografia utilizada no filme figura como uma das características de maior valor na obra. Em 1971, ano de lançamento do filme, produções com coloração fotográfica preto e branco cessaram sua presença entre as mais populares em decorrência do alto custo, da baixa demanda e da dificuldade em se encontrar os materiais necessários para esse tipo de expressão. Entretanto, em Johnny vai à guerra, o uso que é exercido através do misto entre a fotografia colorida e preto e branco vai muito além do mero recurso estético como era costume em outras criações, configurando-se, como resultado dessa opção, em um meio narratológico para a representação das várias instâncias físicas e psicológicas da obra, fato esse que fica bastante evidente quando contrastamos as diferenças entre as fotografias preto e branco, colorida e esfumaçada.

A primeira cena do filme, em preto e branco, é direcionada à introdução do expectador à situação da personagem. Sua construção faz uso do processo de focalização do narrador através da personagem, ao posicionar a câmera de baixo para cima, simulando, dessa forma, o ponto de vista deste, preconizando aquela que será a função do narrador durante todo o filme. Precedida apenas pelos créditos que, ao utilizarem várias cenas originais da Primeira Guerra Mundial, nos dão o tema da narrativa, a cena marca o tom desesperador e claustrofóbico que será mantido sempre que tivermos a recorrência do preto e branco. Tendo início apenas com a respiração da personagem, ela nos exibe a descrição dos médicos do estado clínico do paciente, de maneira inquietante para o espectador, e contradiz a expectativa que é criada pelo ponto de vista inicial da câmera que, auxiliado pela forma do enquadramento, nos engana, nos transmitido a ideia que é com os olhos destruídos da personagem Johnny que vemos a cena (aos 3 min.).

A primeira transição para o colorido acontece ainda nos primeiros minutos da narrativa, quando a personagem entra em um estado que paira entre a lembrança e o sonho. Mesmo sem grandes momentos com ela em seu mundo preto e branco, ou ainda, sem termos visualizado seu estado físico, o narrador nos leva, através de uma leve mudança, para o último dia antes de a personagem ir para a guerra (7 min.). Na ocasião, o acompanhamos em uma visita à casa de sua namorada, Kareen. Em uma cena que nos remete à que acontece no livro, a personagem encontra-se envolta em uma escuridão 
semelhante a cena que a precedeu no leito do hospital, sendo perceptível a transição gradativa de uma cena para a outra pela mudança da coloração, primeiro azulada, e só então, para a em cores. A cena segue até o casal ser interrompido pelo pai de Kareen, que compreendendo a partida iminente de Johnny para a guerra, permite que ele durma com sua filha, uma vez que seu retorno do campo de batalha poderia não acontecer. O misto entre sonho e lembrança já aparece nessa cena, pois uma vez dentro do quarto, é notável uma leve mudança na fotografia, ganhando um tom levemente esfumaçado que, como veremos mais à frente, será característico dos delírios e sonhos da personagem.

Entretanto, as distinções entre esses dois momento, lembrança e sonho, são, em grande parte, mínimas. Isso acontece por que "nós não 'vemos' somente objetos físicos, mas memórias, ideias abstratas, relações, e assim por diante [...]" (CHATMAN, 1992, p. 139). Essa mistura entre lembrança e sonho acontece constantemente durante a narrativa, de forma que em alguns momentos podemos confundir devaneio e lembrança, ou mesmo não conseguir, como no exemplo acima citado, desenvolver um discernimento claro entre eles.

É natural que, semelhante ao que acontece no livro, o narrador câmera coopere com esse tipo de confusão. Uma cena que reflete bem essa característica acontece quando a personagem confunde pesadelo e realidade ao imaginar haver um rato tentando devorar o seu rosto. Isso acontece enquanto a personagem lembra dos fatos presenciados durante a guerra, quando os corpos dos soldados mortos serviam de alimento para esses animais (45 min.).

A cena é construída a partir da descrição desenvolvida pela própria personagem acerca dos movimentos do animal pelo seu corpo, sendo toda a movimentação da câmera um acompanhamento dessa narração. De maneira bastante sutil, é perceptível uma leve coloração azul envolta na escuridão da sala, bem como o tom vermelho do sangue que ele estaria tomando na veia, sendo essa a única vez que teremos o "mundo real" da personagem sendo representado a cores, exatamente por essa representação ser uma configuração direta de sua mente. Essa atmosfera de terror, criada durante o momento em que é desenvolvido o pesadelo, é subitamente interrompida pelo 
retorno da fotografia em preto e branco, quando comprovamos que, na verdade, o que a personagem estava sentindo, era apenas o toque da mão da enfermeira que cuidava dos ferimentos do seu rosto.

A maneira mais fácil de identificarmos essa diferença entre lembrança e sonho, uma vez que a fotografia pode configura-se como falha pela sua submissão à personagem, é analisando a própria construção narrativa usada nesse tipo de cena, de maneira que será o caráter de semelhança com a realidade que delimitará essa distinção. As lembranças serão marcadas pela relação das cenas com fatos explicitamente palpáveis, em contrapartida direta aos sonhos e delírios, que se configuram com uma estrutura sem nexo e, por vezes, inconstantes e inconsistentes.

Se compararmos algumas cenas levando em conta esse "teor do real", podemos facilmente discernir esses dois fatos. Por exemplo: em certo momento da narrativa a personagem apresenta várias memórias referentes a sua infância que, apesar de serem desconexas uma das outras, são todas concretas e comprovadamente possíveis de haverem ocorrido (33 min.). Nelas, vemos, em fotografia colorida levemente esfumaçada, uma sequência de lembranças da personagem quando criança interagindo com seus pais em várias situações: no dia-a-dia, no natal e em tarefas que ele costumava fazer com o pai, como cuidar de uma colmeia caseira, pescar ou ir à Igreja.

Em contrapartida, os sonhos sempre apresentam um "caráter não natural": são desconexos, caoticamente construídos e fundamentados no terreno do fantástico ou fantasioso. Vemos isso, por exemplo, na cena em que a personagem sonha que seu pai o está exibindo como uma aberração de circo (59 min.). Nessa sequência, temos vários fatos que beiram o absurdo como: 1) a cena se passa no meio de um deserto; 2) o pai de Johnny discursa para uma plateia inexistente - fica claro na narrativa que ele já havia falecido; 3) Kareen, namorada da personagem, recolhe o dinheiro dessa plateia; 4) a própria presença da personagem no local, completo e ainda com o fardamento do exército, haja visto que ele já se encontraria em exibição no palco.

Esse mesmo esfumaçamento, que muitas vezes se mistura com os sonhos e lembranças, diretamente, quando de sua utilização exagerada, será responsável pela representação das alucinações e devaneios da personagem, 
que tomam parte, em sua maioria, quando ela se encontra sob o efeito de sedativos ou de profundo envolvimento emocional e psicológico.

O desenvolvimento da cena que será analisada toma lugar logo após um dos momentos mais dramáticos da narrativa. Aos poucos, a personagem começa a perceber a complexidade dos ferimentos sofridos por ele, idealizando, membro após membro, o quanto o seu corpo foi comprometido. A cena é construída de maneira a sentirmos pena da personagem e raiva do médico, uma vez que temos a narração da personagem acerca dos fatos se misturando com a fala deste, passando-nos a impressão de que ele parece não ligar para os gritos de terror do Johnny (25 min.).

Por fim, a personagem desenvolve vários questionamentos sobre o porquê de os médicos haverem optado por deixá-lo daquela maneira, argumentando se seria por motivos econômicos, científicos ou apenas sádicos. No momento específico em que a cena toma lugar, é perceptível, pelo tom de voz usado pela personagem, que ele não se encontra em um estado psicológico normal, uma vez que sua fala apresenta uma narração lenta e com um tom mais calmo do que o de costume. É exatamente nesse momento que observamos o desenvolvimento da perspectiva narratológica do delírio da personagem, que, de maneira desfocada e esfumaçada, expõe a falha psicológica dele (32 min.). Sob efeito das drogas injetadas durante o tratamento, a personagem delira sobre uma possível utilização sua para o exército como um tipo de cobaia de testes para que outros não sofressem aquilo que ele sofria no momento. Mais especificamente, ele se imagina em um tipo de apresentação, na qual o médico o expõe como o ápice da medicina moderna.

De fato, é interessante como, conjuntamente, todos os recursos usados no filme cooperam e se adaptam às necessidades do narrador câmera. Seja a fotografia, como já analisamos anteriormente, o cenário, a própria voz das personagens, a trilha sonora, ou o próprio som, tudo vem a contribuir para a instância narrativa da película. No nosso caso, onde temos por corpus uma construção limitada pela incapacidade motora e comunicativa da personagem, todo e qualquer recurso presente serve para implementar a compreensão das diversas nuances fílmicas. 
Por se limitar a mostrar o ambiente que circunda a personagem, a câmera se vê na dependência do máximo de recursos imagéticos que compõem a ambientação do cenário para substituir elementos que se encontram atenuados em decorrência do método focalizador utilizado por ela. De fato, o espaço e sua composição podem até passar despercebidos, ou ainda, ter sua análise dispensada em narrativas mais tradicionais; porém, em instâncias ímpares como a do filme em questão, cada detalhe na composição do quadro contribui, de alguma forma, para a instância narrativa.

A narração desenvolvida no filme, apesar de aparentar, em um primeiro momento, limitações insolúveis, ao ser analisada com um maior cuidado, apresenta vários pontos de destaque. Não obstante essas várias limitações narrativas herdadas da sua obra fonte, fatores esses que poderiam vir a dificultar o processo de narração da história, vemos que o diretor consegue, de maneira bastante elaborada e peculiar, fazer uso de todos os elementos narrativos disponíveis para construir sentido, partindo desde o uso das mais variadas fotografias a, até mesmo, o uso do ambiente como recurso externo.

\section{Considerações finais}

Ao tomarmos por base a análise aqui desenvolvida, constatamos que sua construção vai muito além de algo banal. Na verdade, em um pensamento totalmente oposto a esse, a adaptação passa a representar a possibilidade de um novo viés, a partir do qual temos a liberdade de, além de contemplar a materialização da obra em uma mídia diferenciada, modificar e atualizar a temática das dessas produções para culturas e épocas diferentes.

Em se tratando de uma adaptação, e com base em tudo que já foi discutido anteriormente acerca da teoria da área, Johnny vai à guerra em nada deixa a desejar. Temos expressa na tela toda a complexidade que nos é familiar à obra, apesar das várias simplificações e aplanamentos desenvolvidos pelo diretor com o intuito de aproximá-la de seus expectadores, bem como de tornar a narrativa mais "didática" em contrapartida a complexidade de sua fonte. 
Embora sejam contextualizadas na Primeira Guerra Mundial, as obras conseguiram atualizar bem a temática para as suas épocas, considerando o lançamento do romance ser um libelo anti-belicista lançado à beira da Segunda Guerra Mundial e, especialmente, a adaptação ter sido produzida em um período estratégico da história, no qual os Estados Unidos ainda se encontravam envolvidos na guerra no Vietnã, fator que validou, mais uma vez, o teor crítico, fomentando o debate envolvendo o papel do país e seus cidadãos na guerra, bem como levantando todo um leque de possibilidades de análises acerca das relações sociais decorrentes desses conflitos.

\section{Referências}

CHATMAN, S. Coming to terms: the rhetoric of narrative in fiction and film. New York: Cornell University, 1990.

HUTCHEON, L. Uma teoria da Adaptação. Florianópolis: UFSC, 2011.

JOHNNY VAI À GUERRA. Direção: Dalton Trumbo. Produção: Bruce Campbell, Tony Monaco, Christopher Trumbo e Tom Tryon. Intérpretes: Timothy Bottons, Kathy Fields, Marsha Hunt, Jason Robards, Donald Sutherland, Charles McGraw, Sandy Brown Wyeth e outros. Roteiro: Dalton Trumbo. [S. I.] World Entertainment, p1971. (111 min.) Color; P\&B.

POUILLON, J. O tempo no romance. São Paulo: Universidade de São Paulo: 1974.

STAM, R. Teoria à prática da adaptação: da fidelidade à intertextualidade. In: Ilha do Desterro: A Journal of English Language, Literatures in English and Cultural Studies. Florianópolis: Editora da UFSC, 2006. p. 19-53.

TRUMBO, D. Johnny got his gun. New York: Bantam Books: 1989.

XAVIER, I. Do texto ao filme: a trama, a cena e a construção do olhar no cinema. In PELLEGRINI, T. et ali. Literatura, cinema e televisão. São Paulo: Senac, 2003. p. 61-89.

Recebido em 23 de março de 2017.

Aceito em 15 de abril de 2017. 